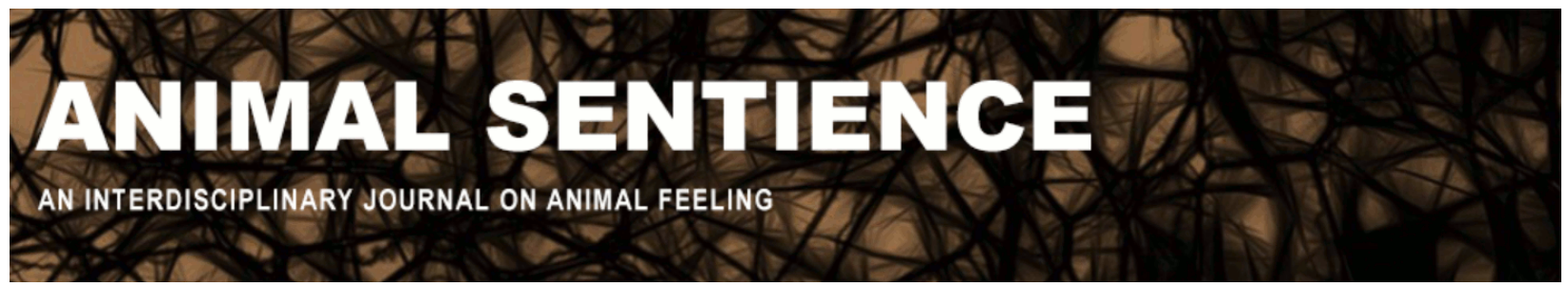

Davis, Tyler; Ireland, Molly E; Van Allen, Jason; and Worthy, Darrell A (2020) Zoonotic realism, computational cognitive science and pandemic prevention. Animal Sentience 30(23) DOI: $10.51291 / 2377-7478.1652$

Date of submission: $2020-10-26$ Date of acceptance: $2020-10-29$

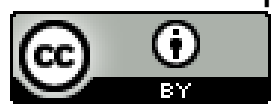




\title{
Zoonotic realism, computational cognitive science and pandemic prevention
}

Commentary on Wiebers \& Feigin on Covid Crisis

\author{
Tyler Davis, Molly E. Ireland, Jason Van Allen \\ Department of Psychological Sciences, Texas Tech University \\ Darrell A. Worthy \\ Department of Psychology, Texas A\&M University
}

\begin{abstract}
Using animals in food and food production systems is one of many drivers of novel zoonoses. Moving toward less dependence on animal proteins is a possible avenue for reducing pandemic risk, but we think that Wiebers \& Feigin's proposed change to food policy (phasing out animal meat production) is unrealistic in its political achievability and its current capacity to feed the world in a cost-effective and sustainable manner. We suggest that improvements in communication strategies, precipitated by developments in computational cognitive neuroscience, can lead the way to a safer future and are feasible now.
\end{abstract}

Tyler Davis is Associate Professor of Psychological Sciences at Texas Tech University. His research is in computational neuroscience and its applications to health and consumer topics. Current projects focus on how cognitive processes contribute to One Health topics such as adoption of food and animal welfare technologies and zoonosis. Website

Molly Ireland is Assistant Professor of Psychological Sciences at Texas Tech University. She studies how language influences and reflects social processes underlying physical and mental health. She uses computational linguistic methods to study One Health issues such as health behavior intentions and social perception in pandemics. Website

Jason Van Allen is Associate Professor of Psychological Sciences at Texas Tech University. He studies individual characteristics and environmental factors associated with health behavior, including the role of humananimal interactions in health outcomes. Website

Darrell Worthy is Associate Professor of Psychological and Brain Sciences at Texas A\&M University. He studies individual differences in learning and decision-making. His current work focuses on how individual differences in personality, age, and other factors predict differences in decision-making behavior. Website
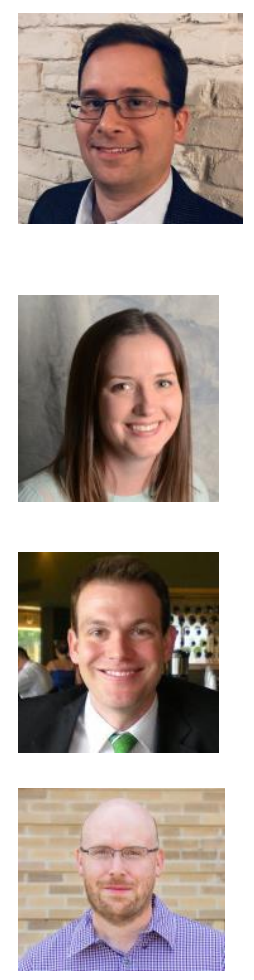

1. Beyond Meat Zoonoses. COVID-19 has changed many aspects of our lives. Academics now write from home instead of university offices. Some changes reduce COVID-19 risk while increasing other zoonotic risks. Outside my (i.e., TD's) home office window are bird feeders. Feeding birds is a tradition learned from my grandmother in the Eastern US. It comes with risks. Birds carry risky zoonoses, including salmonella, trichomoniasis, and coccidiosis. Here on the American Frontier, one can catch even scarier infections from mammals scavenging from those feeders. Rodents may carry hantavirus, a respiratory disease deadlier than COVID-19 and transmissible via aerosolized bodily fluids (Mantooth, et al. 2001). Another, Yersinia Pestis, is endemic in the fleas carried by frontier creatures like prairie dogs and foxes (McGee, et al., 2006). Now curable, Yersinia Pestis decimated cities worldwide for millennia as the disease Europeans called Black Death. Perhaps governments 
could ban feeding birds, but it is hard to imagine that happening democratically, given the value the tradition has to many. The risks can be more effectively mitigated through communications about protective strategies -- wearing protective gear, reducing mammalian access, and handwashing, and by seeking cures for present and future zoonoses as we have for zoonoses of the past.

Zoonotic disease epidemics that have arisen in the cracks between those mentioned in the target article (HIV, Ebola, COVID-19) paint a similar picture. Nipah virus is an emerging infectious encephalitis associated with recent outbreaks in Southern Asia. As with COVID-19 and Ebola, bats are implicated, but instead of consumption of bats, human Nipah infections often originate from urine or salivary contamination of palm sap used for beverages (Luby, et al., 2006). Bats play a significant role in global ecosystems and agriculture (Food and Agriculture Organization of the United Nations, 2011). They are primary pollinators of some crops (like durians; Bumrungsri, et al., 2009); they control crop pests and mitigate human and livestock zoonoses like West Nile, Zika virus, and Malaria. Any human-bat interaction could give rise to the next global pandemic, but we mitigate such risks through effective communication instead of fear and retaliation against bats (Davis et al., 2013; MacFarlane \& Rocha, 2020).

2. Consensus and Collateral Damage. The use of animal protein for food is a significant driver of zoonoses (Wiebers \& Feigin, 2020; W\&F). Modern agriculture can theoretically precipitate novel infectious diseases, as does the use of wild game meat. However, like other drivers, it is difficult to see a democratic path forward to full bans or even immediate large scale changes in consumption practices. Here on the Great Plains, the so-called 'factory farms' are predominantly family ranches. Hunting in rural areas is a tradition that provides high quality protein and - when carried out with stewardship (Holsman, 2000; Waller et al., 2018) - can control wild animal populations humanely. Meat preparation and consumption provides a cultural link to the past for people of many backgrounds. The "wet markets" of Asia and Africa, although often xenophobically described in popular media as hotbeds of disease risk, are often simply the local farmers' markets where produce and meats are sold, and cultural knowledge is transmitted. Robbins (2020) warns against the 'easy solution' of simply shutting down consumption of animal proteins. Indeed, it is easier in theory than it would be in practice. Worldwide demand for meat is ever-increasing, and laboratory grown meat (Anomaly, 2020) is vastly more energy-intensive and costly than ranching at this stage (Tomiyama, et al., 2020). Ending meat consumption globally would exacerbate existing nutritional disparities, both within lower socioeconomic strata of industrialized nations and within developing nations where nutritional deficiencies due to lack of high-quality protein and dietary iron still abound (Allen, 2003).

3. Technology Neophobia. Technological advancements in food production and animal welfare practices are the One Health solutions (Fox, 2020) we need for a safer future--if people will have them. People are notoriously neophobic when it comes to food technologies, including the plantbased and cultured meat alternatives W\&F's target article advocates (He, et al., 2020). Genetically modified crops are decades old and offer substantial benefits to food security and sustainability but still face resistance from consumers (Lusk, et al., 2014). The organic ideal favored by some commentaries is neither efficient enough to provide food for the world's population nor does it provide a safer meat-consumption model (Garcia \& Teixeira, 2017). Small farms with few animals increase the number of unique human-animal contacts in unique environments, which is precisely how low-probability events like novel zoonotic infections arise.

To reduce zoonosis risk, we must support technologies that increase food production whilst reducing the total number of animals used. Examples of misinformation about technologies abound, such as implicating hormone use with antibiotic resistance (Cao, 2020). Hormones are not antibiotics and play no role in antibiotic resistance or zoonotic disease transmission. They do safely increase yields, lowering the number of animals and natural resources needed per animal to produce the same amount of meat (Avery \& Avery, 2007). Computational cognitive science can help build a 
better understanding of the factors that drive human food neophobia (Davis et al., 2020), paving the way toward better acceptance of vaccines, GMOs, hormone replacement, and other strategies to promote One Health and sustainability. Strategies gleaned from this research may someday convince consumers to eat cultured meat.

4. Effective Communication Through Cognitive Science. There are a wide range of zoonoses and no single way to prevent the next pandemic. Preventing outbreaks depends on better communication. Our team has examined ways that computational cognitive science can be used to craft communications about zoonoses and improve outcomes (Davis et al., 2013; 2017; Davis et al., in press). These strategies harness the power of human generalization (inductive reasoning) by tailoring communications either to increasing peoples' wariness of a wide range of species (Tapp et al., 2018) or to limiting their perceptions of risk to a few species or specific drivers of emerging zoonoses. Such principles have shown success at increasing people's intention to avoid wild game meat and other risky human-animal interactions for a variety of zoonotic diseases, including Ebola.

\section{References}

Allen, L. H. (2003). Interventions for micronutrient deficiency control in developing countries: past, present and future. The Journal of nutrition, 133(11), 3875S-3878S.

Anomaly, Jonathan (2020) Cultured meat would prevent the next Covid crisis. Animal Sentience 30(5)

Avery, A., \& Avery, D. (2007). The environmental safety and benefits of growth enhancing pharmaceutical technologies in beef production. Hudson Institute, Center for Global Food Issues, Washington, DC.

Bumrungsri, S., Sripaoraya, E., Chongsiri, T., Sridith, K., \& Racey, P. A. (2009). The pollination ecology of durian (Durio zibethinus, Bombacaceae) in southern Thailand. Journal of Tropical Ecology, 85-92.

Davis, T., Goldwater, M. B., Gaylord, N., Worthy, D. A., Otto, A. R., \& Glass, B. D. (2013). The cognitive psychology of human-bat interactions: Implications for ecological policy and zoonotic disease transmission. Bats: phylogeny and evolutionary insights, conservation strategies and role in disease transmission. Nova, Hauppauge, 1-7.

Davis, T., Goldwater, M. B., Ireland, M. E., Gaylord, N., \& Van Allen, J. (2017). Can you catch Ebola from a stork bite? Inductive reasoning influences generalization of perceived zoonosis risk. PloS One, 12(11).

Davis, T., LaCour, M., Beyer, E., Finck, J. L., \& Miller, M. F. (2020). Neural correlates of attitudes and risk perception for food technology topics. Food Quality and Preference, 80, 103836.

Davis, T., LaCour, M., Goldwater, M., Hughes, B., Ireland, M.E., Worthy, D.A., Gaylord, N., Van Allen, J. (in press). Communicating about diseases that originate in animals: Lessons from the psychology of inductive reasoning. Behavioral Science \& Policy.

Food and Agriculture Organization of the United Nations (FAO). (2011). Investigating the role of bats in emerging zoonoses: Balancing ecology, conservation and public health interests. FAO animal production and health manual no. 12.

Fox, Michael W. (2020) One planet, one health. Animal Sentience 30(6)

Garcia, J. M., \& Teixeira, P. (2017). Organic versus conventional food: A comparison regarding food safety. Food Reviews International, 33(4), 424-446.

He, J., Evans, N. M., Liu, H., \& Shao, S. (2020). A review of research on plant-based meat alternatives: Driving forces, history, manufacturing, and consumer 
attitudes. Comprehensive Reviews in Food Science and Food Safety, 19(5), 26392656.

Holsman, R. H. (2000). Goodwill hunting. Exploring the role of hunters as ecosystem stewards. Wildlife Soc B, 28(4), 808-816.

Luby, S. P., Rahman, M., Hossain, M. J., Blum, L. S., Husain, M. M., Gurley, E., ... \& Kenah, E. (2006). Foodborne transmission of Nipah virus, Bangladesh. Emerging infectious diseases, 12(12), 1888-1894.

Lusk, J. L., Roosen, J., \& Bieberstein, A. (2014). Consumer acceptance of new food technologies: causes and roots of controversies. Annual Review of Resource Economics, 6, 381-405.

Mantooth, S. J., Milazzo, M. L., Bradley, R. D., Hice, C. L., Ceballos, G., Tesh, R. B., \& Fulhorst, C. F. (2001). Geographical distribution of rodent-associated hantaviruses in Texas. Journal of Vector Ecology, 26, 7-14.

McGee, B. K., Butler, M. J., Pence, D. B., Alexander, J. L., Nissen, J. B., Ballard, W. B., \& Nicholson, K. L. (2006). Possible vector dissemination by swift foxes following a plague epizootic in black-tailed prairie dogs in northwestern Texas. Journal of Wildlife Diseases, 42(2), 415-420.

Tapp, W. N., Miller, M. F., Gaylord, N., Goldwater, M. B., Ireland, M. E., Van Allen, J., \& Davis, T. (2018). The Impact of Beliefs About Cross-Species Disease Transmission on Perceived Safety of Wild Game Meat: Building a Psychological Approach to Meat Safety. Meat and Muscle Biology, 1(2).

Tomiyama, A. J., Kawecki, N. S., Rosenfeld, D. L., Jay, J. A., Rajagopal, D., \& Rowat, A. C. (2020). Bridging the gap between the science of cultured meat and public perceptions. Trends in Food Science \& Technology, 104, 144-152.

Waller, D. M., \& Reo, N. J. (2018). First stewards: ecological outcomes of forest and wildlife stewardship by indigenous peoples of Wisconsin, USA. Ecology and Society.

Wiebers, D. O., \& Feigin, V. L. (2020). What the COVID-19 Crisis Is Telling Humanity. Animal Sentience 30(1): 1-7. 